process von 14 Tagen sind die Stiicke zum Verkauf bereit. Sechs derselben gehen auf ein Pfund. Man verschifft den Indigo in Kisten von 200 Pfund $\mathrm{zu}$ dem Preise von 600 bis $700 \mathrm{fl}$. Unser Freund van Prehn versendet jährlich 100 bis 120 Kisten, die eine schöne Einnahme (von etwa 80,000 1.) bilden. Zur Erzeugung dieser Quantität verwendet er jahrlich die Bevölkerung der umliegenden Dessas von 3000 Seclen jedes Alters, darunter etwa 700 Männer.

\title{
Ueber das Berberin.
}

Das vom Hofrath Buchner in der Wurzelrinde von Berberis vulgaris entdeckle, und von diesem zu der Classe der sogenannten Untersäuren oder Farbstoffe gerechnete Berberin ist vom Fleitmann einer erneuerten Untersuchung unterworfen, woraus letzterer den Schluss zieht, dass man diesen Stoff zu den organischen Basen rechnen müsse.

Das reine Berberin krystallisirt in feinen gelben Nadeln, welche über Schwefelsäure getrocknet, bei $100^{\circ} \mathrm{im}$ Wasserbade an 19 Proc. Wasser verlieren, wobei dieselben eine rothbraune Farbe annehmen. Bei $120^{\circ}$ schmilzt das Berberin zu einer harzigen Masse, ohne dabei an Gewicht abzunehmen. Im Wasser gelöst, reagirt es (wie auch B u chner fand) völlig neutral. Mit Salzsäure oder Schwefelsäure zusammengebracht, färbt sich die Lösung heller und setzt, bei nicht zu starker Verdünnung, nach einiger Zeit Krystalle des entsprechenden Salzes ab. Mit den Alkalien und alkalischen Erden verband sich das Berberin nicht; jedoch wurde es durch sehr concentrirte Kalilauge zersetzt, wie die meisten organischen Körper.

Da der Vorrath des Berberins nur gering war, so warde in dem reinen Körper nur der Kohlenstoff und Wasserstoff, so wie der Wassergehalt desselben bestimmt. Die Formel aber nach den Analysen der Verbindungen berechnet. In 100 Theilen bis $100^{\circ}$ getrocknet waren:

\begin{tabular}{|c|c|c|c|c|c|c|c|}
\hline \multirow{5}{*}{$\begin{aligned} 42 & \text { Kohlenstoff. } \\
20 & \text { Wasserstoff.. } \\
1 & \text { Stickstoff... . } \\
11 & \text { Sauerstoff... }\end{aligned}$} & & \multicolumn{3}{|c|}{ berechnet } & \multicolumn{3}{|c|}{ gefunden } \\
\hline & 3150 & - & 67,35 & - & 67,35 & - & 66,66 \\
\hline & 25 & - . & 5,35 & - & 5,67 & - & 5,68 \\
\hline & 177 & - & 3,78 & - & ", & & 9 \\
\hline & 110 & - & 23,52 & - & $"$ & & \\
\hline & & & & & & & \\
\hline
\end{tabular}

Da nun das Atomgewicht des wasserfreien Berberins nach der Analyse des chromsauren und der Platinverbindung 44522 ist und die Formel sich hiernach $\mathrm{zu} \mathrm{C}^{42} \mathrm{H}^{18} \mathrm{NO}^{9}$ 
herausstellt, so enthält das bei $100^{\circ}$ getrocknete 2 Atome Wasser.

0,519 von dem unter der Lufipumpe getrockneten Berberin, gaben bei $100^{\circ} \mathrm{C}$. 0,10 Wasser $=19,26$ Proc.. wonach die Formel für das lufttrockne Berberin folgende ist:

$$
\begin{aligned}
& \mathrm{C}^{42} \mathrm{H}^{18} \mathrm{NO}^{9}+2 \mathrm{HO}+10 \mathrm{aq} \\
& \text { Salzsaures Berberin. } \\
& \mathrm{C}^{12} \mathrm{H}^{18 \mathrm{NO}^{9}}+\mathrm{ClH}+5 \mathrm{HO} \text {. } \\
& \text { Saures schwefelsaures Berberin. } \\
& \mathrm{C}^{42} \mathrm{II}^{18} \mathrm{NO}^{9}+2 \mathrm{SO}^{3}+2 \mathrm{IIO} \text {. } \\
& \text { Saures chromsaures Berberin. } \\
& \mathrm{C}^{2} \mathrm{H}^{18} \mathrm{NO}^{\prime}+2 \mathrm{ChrO}^{3} \text {. } \\
& \text { Salpetersaures Berberin. } \\
& \mathrm{C}^{42} \mathrm{II}^{18} \mathrm{NO}^{9}+\mathrm{NO}^{5}+110 . \\
& \text { Chlorsaures Berberin. } \\
& \mathrm{C}^{12} \mathrm{H}^{15} \mathrm{NO}^{3}+\mathrm{ClO}^{5}+110 \text {. } \\
& \text { Berberinplatinchlorid. } \\
& \mathrm{C}^{12} \mathrm{II}^{9} \mathrm{NO}^{9}+\mathrm{ClII}+\mathrm{PlCl}^{2} \text {. }
\end{aligned}
$$

Besonders interessant ist die Verbindung der Chromsảure mil dım Berberin, da man bis jetzt noch keine Verbindung einer organischen Base mit dieser Säure kennt. In der Regel findet gerade beim Zusammentreffen organischer Körper mit Chromsäure eine energische Reaction stalt, welche mil einer theilweisen Zersetzung der letzteren verbunden ist.

Ein eigenthümliches Verhallen zeigt auch das Berberin gegen Mehrfach - Schwefelammonium. In einer salzsauren Berberinlösung bringt ein mit Schwefel gesättigtes Schwe. felammonium augenblicklich einen braunrothen Niederschlag hervor, in welchem der Schwefel nicht mehr in der Form von Schwefelwasserstoff vorhanden ist und durch Bleisolution nicht erkannt werden kann. Durch freie Salzsäure findet keine Gasentwickelung statt. Eine Auflösung dieses Körpers in Wasser gab mil neutralem essigsaurem Bleioxyd einen schönen rothen Niederschlag, welcher einen sehr unangenehmen, dem Mercaptan ähnlichen Geruch besass.

Nach einer vorläufigen Untersuchung dieser Schwefelverbindung scheint dieselbe die Rolle einer Basis zu spielen und mit Säuren Verbindungen einzugehen. Elwas ibber $100^{\circ}$ schmilzl sie wie das Berberin, ohne sich scheinbar zu zersetzen. Eine Schwefelbestimmung gab 16,53 Proc. Schwefel. (Ann. d. Chem. u. Pharm. Bd. 5y. p. 160-177.) 